\title{
Avaliação de Cinco Híbridos de Milho (Zea mays, $L$.) em Diferentes Estádios de Maturação. 3. Composição Químico-Bromatológica ${ }^{1,2}$
}

\author{
Lúcia Maria Zeoula ${ }^{3}$, Juliano Ricardo Fontanini Beleze ${ }^{4}$, Ulysses Cecato ${ }^{3}$, Clóves Cabreira \\ Jobim $^{3}$, Luiz Juliano Valério Geron ${ }^{5}$, Emylin Midore Maeda ${ }^{5}$, Alencariano José da Silva Falcão ${ }^{6}$
}

RESUMO - O objetivo do presente estudo foi avaliar cinco híbridos de milho (Zea mays L.) Pioneer: superprecoce P32R21, os precoces P30R07, P3041 e P30F33 e o semiprecoce P30F80, quanto à composição química, em diferentes estádios de maturação. O delineamento utilizado foi de blocos ao acaso, com cinco tratamentos e quatro repetições. A colheita das amostras dos híbridos de milho foi adotada estimando-se os cinco estádios de maturação da planta: 30, 34, 38, 42 e 46\% de matéria seca (MS). Para cada estádio de maturação, procedeu-se à separação de colmo + bainha, lâmina foliar e do grão para posteriores analises químicas. Da fração grão, foram determinados os teores de nitrogênio total e de amido, nos cinco estádios de maturação. Nas frações de lâmina foliar e colmo + bainha, foram determinados os teores de fibra em detergente ácido (FDA), fibra em detergente neutro (FDN), lignina, nitrogênio insolúvel em detergente ácido (NIDA) e nitrogênio total. Para os parâmetros avaliados observou-se diferença entre os híbridos de milho e efeito de dias pós-plantio. Com o avanço do estádio de maturação, observou-se que houve ligeira redução nos teores de proteína bruta (PB) e os teores de amido praticamente não variaram no grão. Para a fração lâmina foliar, verificou-se que, com o aumento nos teores de matéria seca da planta, houve queda nos teores de PB e NIDA, ao contrário da fração colmo + bainha, cujos teores aumentaram. Os teores de FDN, FDA e lignina na lâmina foliar aumentaram, porém esses nutrientes na fração colmo + bainha dos híbridos de milho, praticamente, não variaram com o avanço do estádio de maturação.

Palavras-chave: composição química, estádios de maturação, grão, colmo, lâmina foliar

\section{Evaluation of Five Corn Hybrids (Zea mays, L.) at Different Maturity Stages. 3. Chemical-Bromatology Composition}

\begin{abstract}
The objective of this study was evaluate, of the chemical composition of five corn (Zea mays L.) hybrids Pioneer: P32R21, P30R07, P3041, P30F33 and P30F80, at different maturity stages. The treatments were used in plots of $7 \mathrm{x} 8 \mathrm{~m}$ in a randomized block design, with four replicates. The samples collected of corn hybrid were adopted trying to estimate phases of maturity of the plant: $30,34,38,42$ and $46 \%$ of dry matter (DM)). For stages of maturity, proceed separation stem + sheath, lamina leaf, and grain at analysis chemicals. In fraction grain, was determinated levels total nitrogen and starch in the different maturation stages. In the fractions of leaf lamina and stem + sheath, levels the following analysis chemicals was determinated: acid detergent fiber (ADF), neuter detergent fiber (NDF), lignin, acid detergent insoluble nitrogen (ADIN) and total nitrogen. All the variables presented differences between the hybrids and days after seeding (DAS). With the advance of the maturity, observed a decrease of crude protein (CP) and of crude starch practicably not varied. For fraction lamina leaf, verification that, increased levels the dry matter at plant, and decreased the levels starch, $\mathrm{CP}$ and ADID, contrary the fraction stem + sheath, increased levels. The levels NDF, ADF and lignin the lamina leaf increased, but this nutrition at fraction stem + sheath the corn hybrid, practicably, not varied with advance the maturity of stages.
\end{abstract}

Key Words: chemical composition, grain, lamina leaf, stages of maturation, stem

\section{Introdução}

Entre as forrageiras utilizadas com o propósito de ensilagem, é o milho a que mais se destaca, sobretudo em razão do seu valor nutritivo e da boa produção de massa por unidade de área plantada. Para esta prática, o milho (Zea mays, L.) é recomendado, tornando-se a espécie padrão, e cujo valor nutritivo é tomado como referência (Bezerra et al., 1993).

O valor nutritivo de uma forrageira é dependente da composição química, do consumo pelos animais, e da digestibilidade de seus elementos nutritivos (Crampton, 1957; Barnes, 1965; Johnson et al., 1985; Demarquilly, 1994; Barrière et al., 1997; Almeida Filho et al., 1999).

\footnotetext{
1 Projeto financiado pela PIONEER SEMENTES, com parceria da FUNDAÇÃO ABC.

2 Parte da Dissertação de Mestrado apresentada pelo segundo autor.

3 Professores do PPZ/ DZO/UEM. Av. Colombo, 5790 - CEP: 87020-900, Maringá - PR. Bolsista do CNPq. E.mail: Imzeoula@uem.br

4 Médico - Veterinário, mestre em Produção Animal - PPZ/UEM. E.mail: jbeleze@hotmail.com

5 Estudante de graduação em Zootecnia - DZO/ UEM - Bolsista de Iniciação Científica/ CNPq.

${ }^{6}$ Estudante de doutorado em Melhoramento Genético - PPZ/UEM.
} 
A determinação do ponto ótimo de colheita demanda o conhecimento do comportamento da cultura, em termos de produção de matéria seca digestível e composição da planta. Assim, para produzir uma silagem de milho de boa qualidade é necessário que a colheita seja feita no estádio adequado de maturidade.

Um grupo de pesquisadores do Instituto Nacional de Pesquisa da França (INRA) de Lusignan (1998), concluíram que a qualidade do grão de milho e da fração verde da planta (caule, folha e palha), e o que variou com avanço do estádio de maturação da cultura é que irão determinar o valor nutritivo da silagem. De modo que, o uso de silagem de variedades de milho com colmos de melhor digestibilidade e teor de grão normal para vacas em lactação permitirão produzir mais leite, com menor quantidade de concentrado na ração (economia de 1,0 a 1,5 kg de concentrado/animal/dia).

Segundo os pesquisadores da Empresa Brasileira de Pesquisa Agropecuária (Embrapa, 1997), existe grande correlação entre o valor nutritivo de uma cultura de milho e o de sua silagem. Dessa maneira, avaliando-se a planta fresca e seus componentes, será possível estimar a qualidade da futura silagem desta planta.

Hunter (1978), após revisão sobre os fatores que influenciam na qualidade da silagem, questionou a importância da participação de grãos como o principal responsável pela qualidade e produtividade da silagem de milho. Esse autor apontou uma variação genotípica para a qualidade da planta dentro dos materiais utilizados para produção de grãos. Essas diferenças genotípicas são expressas através do consumo de matéria seca (MS) e da digestibilidade da forragem e não dependente da relação grão/planta. Desse modo, ele concluiu que, para melhorar a qualidade da silagem, é necessário que a parte não constituída de grãos seja também de boa qualidade.

O teor de MS na planta inteira aumenta de 14 a $16 \%$ no estádio de floração, para 33 a 35\% de MS, quando chega no estádio de grão farináceo-duro, ou seja um aumento de 0,35 unidades de MS/dia, para Região de Clermont-Ferrand (França). O aumento no teor de MS é devido ao crescimento da espiga na planta e do teor de MS da espiga. Por outro lado, os teores de cinza, nitrogênio, celulose diminuem ligeiramente, enquanto que, o teor de glicídios solúveis diminui rapidamente em beneficio do teor de amido (Andrieu, 1993).
O teor de MS da silagem de milho é fator essencial na quantidade de energia ingerida pelos bovinos. Numa revisão realizada por Demarquilly (1994), observou-se aumento na ingestão de MS da silagem de milho fornecida a bovinos, quando os teores de MS aumentaram até atingir 35\%. Estes resultados podem ter ocorrido devido à diminuição no teor de parede celular e aumento no teor de grãos (o teor de MS e o teor de grão evoluem paralelamente). Ainda, Demarquilly (1994) observou que vacas leiteiras apresentaram consumo de MS, variando de 12,0 a $15,3 \mathrm{~kg} \mathrm{MS} /$ dia, quando ingeriram silagem de milho com teor de MS, variando de 25 a 35\%. Raymond et al. (1986), citados por Demarquilly (1994), mostraram que, na faixa de 25 a $35 \%$ de MS no milho, para cada aumento de 5 pontos no teor de MS, corresponde, em média, um aumento no teor de grão de $5,7 \%$ e na velocidade de crescimento de novilhos, de $4 \%$.

Segundo Almeida Filho et al. (1999), os teores de FDN (\% na MS) de nove híbridos (Zeneca 8501; Braskalb XL 380; Agroceres 5011; Embrapa 206; Cargil 435; Agroceres 1051; Pioneer 3071; Zeneca 8447; Embrapa HT-2X) variaram de 58,1 a 63,3\% e não diferiram entre si, assim como também, os teores FDA (\% na MS) não apresentaram diferenças significativas e variaram de 28,8 a $31,7 \%$.

O estádio ótimo de colheita registrado na literatura é quando a quantidade de MS/ha é máxima e isto ocorre quando o grão atinge seu estádio farináceoduro com teor de MS, variando de 33 a $35 \%$. Ainda, com esse teor de MS, obtém-se boas condições de fermentação e conservação da silagem, correspondendo a uma ingestão máxima de forragem pelos bovinos.

Este trabalho foi conduzido com o objetivo de avaliar cinco híbridos de milho (Zea mays, L), quanto à composição químico bromatológica das diferentes frações da planta, colhidos em diferentes estádios de maturação, para produção de silagem.

\section{Material e Métodos}

O plantio dos híbridos de milho Pioneer foi realizado na fazenda experimental "Capão Alto", pertencente à Fundação ABC, formada pelas Cooperativas Arapoti Ltda, Agropecuária Batavo Ltda e Sociedade Cooperativa Castrolanda, localizada no município de Castro, região sul do Estado do Paraná.

As análises químicas bromatológicas foram realizadas no Laboratório de Alimentação e Nutrição 
do Departamento de Zootecnia da Universidade Estadual de Maringá.

O plantio dos híbridos foi realizado em outubro de 1999 e as colheitas das amostras foram iniciadas em fevereiro de 2000, prolongando-se até o final de março de 2000.

$\mathrm{O}$ estabelecimento da cultura foi realizado em uma área plana de solo Latossólico vermelho amarelo. A análise do solo revelou as seguintes características: $\mathrm{pH} 5,1 ; \mathrm{P}-96 \mathrm{mg} / \mathrm{dm}^{3} ; \mathrm{Al}^{+++}-1 \mathrm{mg} / \mathrm{dm}^{3}$; $\mathrm{K}-3,4 \mathrm{cmol} / \mathrm{dm}^{3} ; \mathrm{Ca}^{++}-33 \mathrm{cmol} / \mathrm{dm}^{3} ; \mathrm{H}^{+}+\mathrm{Al}^{+++}$ - $58 \mathrm{mg} / \mathrm{dm}^{3} ; \mathrm{Mg}-17 \mathrm{cmol} / \mathrm{dm}^{3}$ e matéria orgânica $46 \mathrm{mg} / \mathrm{dm}^{3}$.

Para o estabelecimento da cultura de milho, a área foi arada e posteriormente gradeada para destorroamento, nivelamento e abertura dos sulcos. Por ocasião da semeadura, em sulcos espaçados de $80 \mathrm{~cm}$, foi aplicado adubo correspondente a $150 \mathrm{~kg} / \mathrm{ha}$, da fórmula 15-30-0 (N-P-K) e adubação orgânica com esterco bovino 30.000 Litros/ha. Realizou-se também uma adubação em cobertura com $250 \mathrm{~kg} / \mathrm{ha}$, da fórmula 25-0-5 (N-P-K).

Foram avaliados cinco cultivares de milho híbrido Pioneer: superprecoce 32R21 (P32R21), precoce 30R07 (P30R07), precoce 3041 (P3041), precoce 30F33 (P30F33) e semiprecoce 30F80 (P30F80). O delineamento experimental utilizado foi de blocos ao acaso, com cinco tratamentos e quatro repetições.

A colheita das amostras dos híbridos de milho foi adotada tentando obedecer cinco estádios de maturação da planta: 30, 34, 38, 42 e 46\% de MS, totalizando 100 amostras da planta inteira (5 estádios de maturação, 5 híbridos, 4 repetições). Com a finalidade de se alcançar os cinco estádios de maturação, observou-se o dia pós plantio (DPP), que correspondeu ao dia em que as amostras de cada híbrido foram colhidas no campo, obedecendo uma ordem cronológica (ciclo de pendoamento de cada híbrido), monitoramento da consistência do grão nas plantas da bordadura e a utilização de dados referentes à MS dos mesmos híbridos, plantados no mesmo período, mas em ano anterior.

A parcela experimental foi constituída de 11 linhas de sete metros de comprimento e com espaçamento de $80 \mathrm{~cm}$, totalizando oito metros de largura, portanto, a área de cada parcela utilizada correspondeu a $61,6 \mathrm{~m}^{2}$. Foi considerada uma área útil de $36 \mathrm{~m}^{2} \mathrm{em}$ cada parcela, sendo que duas linhas laterais e hum metro das duas extremidades foram consideradas como bordaduras, portanto, as amostras foram obtidas das nove linhas restantes, fazendo-se uso de toda parcela experimental.
Em todos os estádios de maturação foram colhidas três plantas/linha/parcela, totalizando 27 plantas amostradas/parcela (9 linhas na parcela). A colheita foi precedida de sorteio, desprezando-se plantas fora do padrão (outlier $=2$ plantas/cova) e preocupou-se em não retirar plantas seguidamente, para evitar possíveis espaços (clarões) entre plantas, que pudessem também conduzir a um efeito competitivo entre elas. Das 27 plantas colhidas, uma foi utilizada para amostra de planta inteira, e as demais, para amostras de colmo + bainha, lâmina foliar e grão, em cada estádio de maturação. Depois de corte realizado a $45 \mathrm{~cm}$ do solo, com foice, todas as plantas da mesma parcela eram agrupadas, identificadas e transportadas para um local apropriado.

Para cada estádio de maturação, procedeu-se à pesagem da massa verde de cada planta colhida, individualmente e, posteriormente, foi feita a separação de colmo + bainha, lâmina foliar, grão, sabugo e palha para pesagem destes.

Para cada estádio de maturação, procedeu-se à pesagem (balança com capacidade de $15 \mathrm{~kg}$ ) da massa verde de cada planta colhida, individualmente e, posteriormente, foi feita a separação de colmo + bainha, lâmina foliar, grão, sabugo e palha para pesagem destes.

Após a pesagem, todo o material colhido foi triturado em tamanho de aproximadamente $2 \mathrm{~cm}$ por meio de picadeira de forragens, com exceção do grão. Após a homogeneização da forragem picada, foram retiradas amostras em torno de $500 \mathrm{~g}$, pesadas em balança com capacidade de $3 \mathrm{~kg}$ e foram présecas em saco de papel, em estufa a $55^{\circ} \mathrm{C}$ com ventilação forçada, até à obtenção de peso constante, para determinação da matéria seca. Para a amostragem dos grãos, retirou-se após homogeneização, amostras de $500 \mathrm{~g}$, seguindo-se o mesmo procedimento adotado para fração verde.

Determinou-se a porcentagem de matéria seca (MS\%) a $105^{\circ} \mathrm{C}$ em estufa sem ventilação, das frações: planta inteira, grãos, lâmina foliar e colmo + bainha, segundo Silva (1998).

Nas frações de lâmina foliar e colmo + bainha (amostras provenientes da homogeneização das 18 plantas por parcela) foram realizadas as seguintes análises: fibra em detergente ácido (FDA), fibra em detergente neutro (FDN), lignina, nitrogênio total e nitrogênio insolúvel em detergente ácido (NIDA), pelo método proposto por Van Soest (1965), citado por Silva (1998). 
$\mathrm{Na}$ fração grão, os teores de amido nos diferentes estádios de maturação, foram obtidos por meio do método enzimático, citado por Poore et al. (1989), seguindo as adaptações de Pereira \& Rossi (1995). A determinação do nitrogênio total das amostras, pelo método Kjeldahl, foram realizadas segundo Silva (1998).

Todas as variáveis foram testadas quanto à sua normalidade e homogeneidade da variância. As análises exploratórias dos dados mostraram que as variáveis não apresentaram distribuição normal $(\mathrm{P}<0,01)$. Então, admitiu-se uma distribuição gama para o erro em um Modelo Linear Generalizado (GLIM 4.0), como descrito por Nelder \& Wedderburn (1972).

\section{Resultados e Discussão}

Houve efeito de dias pós plantio (DPP) sobre os teores de proteína bruta (PB) e amido nos grãos dos híbridos avaliados, cujo comportamento é explicados pelas equações apresentadas na Tabela 1. Para os teores de PB este comportamento foi linear decrescente. Com o avanço do estádio de maturação da planta houve pequena redução nos teores de $\mathrm{PB}$ do grão.

O híbrido superprecoce P32R21, aos 132 DPP (28,88\% MS), apresentava-se com $10,15 \%$ de PB e, aos 137 DPP (34,51\% MS), com 10,05\% de PB. Para o híbrido precoce $\mathrm{P} 30 \mathrm{R} 07$, os teores de $\mathrm{PB}$ variaram de 9,65 e $9,52 \%$, entre 128 (33,13\% MS) e 135 DPP $(35,00 \% \mathrm{MS})$.

Já o híbrido precoce P3041 apresentou os menores valores de $\mathrm{PB}$ de 8,78 e 8,68\%, respectivamente, para os teores de 29,88 (140 DPP) e 34,81\% MS (145 DPP). O híbrido precoce P30F33, aos 131 DPP (29,93\% MS), apresentou 9,41\% de PB e, aos 141 DPP (34,81\% MS), 9,22\% de PB. Para o híbrido semiprecoce P30F80, observou-se, aos 155 DPP $(29,69 \%$ MS ) e 162 DPP (34,78\%), teores de PB que variaram de 9,84 e $9,71 \%$, respectivamente. Os resultados mostraram que não há uma correlação significativa entre os teores de matéria seca da planta e os teores de proteína bruta do grão, obtidos nos diferentes estádios de maturação.

De modo geral, o teor de nitrogênio é estável durante o período de enchimento do grão e da maturação da espiga, quando expresso em relação a MS, entretanto, este teor é reduzido ligeiramente em estádios mais avançados de maturidade (Cabon, 1996). Segundo o autor, a variabilidade noteor de nitrogênioadvém, sobretudo das diferenças entre local e ano de cultivo e de pouca variação entre híbrido cultivados ao mesmo tempo.
Tabela 1 -Valores estimados dos teores de proteína bruta (PB) e amido (AM) dos grãos, dos híbridos de milho, em função dos DPP, nos diferentes estádios de maturação

Table 1 - Estimated values of crude protein $(C P)$ and starch (S) the corn hybrid in function the days after seeding (DAS) at different stages maturity

\begin{tabular}{|c|c|c|c|c|}
\hline $\begin{array}{l}\text { Híbrido } \\
\text { Hybrid }\end{array}$ & $\begin{array}{c}\text { DPP } \\
D A S \%\end{array}$ & $\begin{array}{l}\mathrm{MS} \% \\
D M \%\end{array}$ & $\begin{array}{c}\text { aProteína\% } \\
\text { Protein } \% \\
\end{array}$ & $\begin{array}{c}\text { bAmido } \% \\
\text { Starch }\end{array}$ \\
\hline \multirow[t]{5}{*}{ P32R211 } & 125 & 25,85 & 10,28 & 70,89 \\
\hline & 129 & 27,59 & 10,20 & 71,88 \\
\hline & 135 & 32,62 & 10,09 & 70,64 \\
\hline & 142 & 38,63 & 9,96 & 68,58 \\
\hline & 151 & 39,27 & 9,79 & 72,13 \\
\hline \multirow[t]{5}{*}{ P30R072 } & 128 & 33,13 & 9,65 & 78,18 \\
\hline & 134 & 33,76 & 9,53 & 73,37 \\
\hline & 141 & 39,90 & 9,40 & 74,83 \\
\hline & 149 & 47,40 & 9,25 & 78,64 \\
\hline & 156 & 48,27 & 9,10 & 77,26 \\
\hline \multirow[t]{5}{*}{ P3041 3} & 127 & 26,11 & 9,02 & 79,83 \\
\hline & 134 & 25,42 & 8,89 & 74,74 \\
\hline & 141 & 30,80 & 8,76 & 74,91 \\
\hline & 149 & 38,28 & 8,61 & 77,87 \\
\hline & 156 & 40,46 & 8,48 & 79,57 \\
\hline \multirow[t]{5}{*}{ P30F334 } & 129 & 29,17 & 9,49 & 76,83 \\
\hline & 135 & 31,71 & 9,38 & 74,56 \\
\hline & 142 & 35,35 & 9,25 & 75,21 \\
\hline & 151 & 40,05 & 9,08 & 79,17 \\
\hline & 157 & 42,54 & 8,97 & 82,46 \\
\hline \multirow[t]{5}{*}{ P30F80 5} & 135 & 20,74 & 10,22 & 69,58 \\
\hline & 142 & 25,85 & 10,09 & 73,52 \\
\hline & 151 & 28,37 & 9,92 & 77,03 \\
\hline & 157 & 30,68 & 9,81 & 77,41 \\
\hline & 164 & 37,26 & 9,68 & 74,90 \\
\hline
\end{tabular}

\%MS: \% de matéria seca da planta inteira.

$\% D M: \%$ the dry matter whole plant.

$1 \mathrm{a} \% \mathrm{~PB}=12,64-0,01885^{*} \mathrm{DPP}$

$1 \mathrm{~b} \% A=-5642+126,4^{*} \mathrm{DPP}-0,9297^{*} \mathrm{DPP}^{2}+0,002273^{*} \mathrm{DPP}$

2a $\% P B=12,64-0,5750-0,01885^{\star} D P P$

$2 \mathrm{~b} \% \mathrm{~A}=-5642+14056-175,5^{\star} \mathrm{DPP}+1,2275^{\star} \mathrm{DPP}^{2}-0,002853^{\star} \mathrm{DPP}^{3}$

3a $\% \mathrm{~PB}=12,64-1,217-0,01885^{\star} \mathrm{DPP}$

3b \%A $=-5642+10062-89,53^{*} D P P+0,6124^{*} D P P^{2}-0,00139^{*} D P P^{3}$

$4 \mathrm{a} \% \mathrm{~PB}=12,64-0,7600-0,01885^{\star} \mathrm{DPP}$

$4 \mathrm{~b} \% A=-5642+8015-45,85^{\star} D P P+0,3019^{*} D^{2} P^{2}-0,0006547^{\star} D^{2} P^{3}$

$5 \mathrm{a} \% \mathrm{~PB}=12,64+0,1316-0,01885^{\star} \mathrm{DPP}$

$5 b \% A=-5642+6855-26,51{ }^{*} D P P+0,2002 * D^{*} P^{2}-0,0004931{ }^{*} D^{2} P^{3}$

Os teores médios, estimados, de proteína bruta (PB) do grão dos cinco híbridos de milho avaliados, nos diferentes estádios de maturação, diferiram entre si $(\mathrm{P}<0,01)$. A média geral para o híbrido superprecoce P32R21 foi de 10,06\%, para os híbridos precoces P30R07, P3041 e P30F33 foram, respectivamente, de $9,38 \%, 8,75 \%$ e $9,23 \%$ e para o híbrido semiprecoce P30F80 foi de 9,94\% de PB. Os valores observados são próximos aos relatados por Johnson et al. (1985), que encontraram variações nos cultivares de milho de 8,2 a $14,2 \%$, iguais aos resultados divulgados pela Embrapa (1997) e superiores a outros resultados 
encontrados na literatura (Almeida Filho, 1996; Guimarães, 1997).

Para os teores de amido no grão verificou-se um comportamento cúbico $(\mathrm{P}<0,05)$ em função de DPP, porém não foi observado diferença nos teores de amido ( $\mathrm{P}>0,01)$ entre híbridos. Segundo Mayombo et al. (1997), os teores de amido aumentam com o avanço do estádio de maturidade (25,1 a 32,3\% de MS).

Considerando a faixa ideal de 30 a $35 \%$ de MS, para o processo de ensilagem, observou-se que o híbrido semiprecoce P30F80 apresentou destaque frente aos outros híbridos, com variação de 77,51 a $76,00 \%$ de amido, com 155 (29,69\% MS) e 162 DPP $(34,78 \%)$. Para o híbrido superprecoce P32R21, esta variação no teor de amido foi de 71,53 a 69,95\%, para os híbridos precoces P3041, P30F33 e o híbrido P30R07 foi, respectivamente, de 74,68 a 76,27; 75,73 a 74,95 e 78,18 a 73,23\% de amido (Tabela 1).

O comportamento cúbico para os teores de amido no grão em função dos DPP pode ser explicado pelo efeito de concentração de outros nutrientes no grão (extrato etéreo, carboidratos solúveis, matéria mineral, vitaminas, parede celular), que podem variar com o avanço do estádio vegetativo da planta e, ainda, através do processo de translocação de nutrientes entre as estruturas da planta de milho. Este raciocínio serve para discussão das demais variáveis analisadas neste trabalho. Portanto, em determinadas circunstâncias experimentais, torna-se importante conhecer a maneira pela qual a matéria orgânica produzida é distribuída pelos vários órgãos da planta. As linhas alométricas características dos vários órgãos da planta, durante o crescimento, seguem direções diferentes, indicando alterações na distribuição dos metabólitos através da planta (Ferri, 1985).

Cabon (1996) observou que o acúmulo de amido é bloqueado pela falta de calor e pela falta de água e estes fatores são mais acentuados nos híbridos mais precoces, em relação aos mais tardios.

Os valores médios obtidos, nos cinco estádios de maturação, para os teores de amido de 70,82, 76,45, $77,38,77,64$ e 74,50\% para os híbridos P32R21, P30R07, P3041, P30F33 e P30F80, respectivamente, encontram-se dentro da variação de $72,1 \pm 6,4 \%$ de amido no grão de milho, registrada na literatura (Arieli et al., 1995; Johnson, 1998; Caldas Neto et al., 2000; Fregadolli et al., 2001).

Andrieu et al. (1993) relataram que os teores de amido e de fibra estão inversamente correlacionados, cujos coeficientes de correlação foram de
$R^{2}=-81,6 \%$ entre amido e celulose e de $R^{2}=-84,7 \%$ entre amido e fibra em detergente ácido. Os autores concluíram que o teor em fibra permanece constante durante o enchimento do grão. No presente trabalho, foi observada correlação negativa entre o teor de amido no grão e a proporção de colmo + bainha $\left(\mathrm{R}^{2}\right.$ $=-54,75 \%$ ) em relação à planta inteira.

Estudos realizados no INRA (Institut National de la Recherche Agronomique - França, 1998) revelaram que o teor de grãos não é suficiente para predizer o valor alimentar da silagem de milho, devendo-se considerar também a composição química da fração verde, bem como a sua digestibilidade.

Avaliando-se os teores de proteína bruta da lâmina foliar, dos híbridos de milho, observou-se efeito cúbico $(\mathrm{P}<0,01)$ para DPP (Tabela 2). Verificou-se que quando os teores de MS da planta inteira variaram de 25 a $45 \%$ os teores de PB apresentaram-se decrescentes. Considerando teores de MS, da planta inteira, entre 30,00 a $35,00 \%$, para os híbridos superprecoce P32R21 e o precoce P3041, os teores de PB variam de 11,41 a $10,50 \%$ e de 12,02 a $11,39 \%$, respectivamente e, para ohíbrido semiprecoce $\mathrm{P} 30 \mathrm{~F} 80$, observou-se valores entre 10,69 e 9,19\% PB. O teor de PB da lâmina foliar do híbrido precoce P30F33 variou de 13,87 (29,93\% MS, $131 \mathrm{DPP})$ a $11,68 \%$ (35,00\% MS, 141 DPP) e do híbrido precoce P30R07 variou de $13,43(33,13 \% \mathrm{MS}, 128 \mathrm{DPP})$ a $11,90 \%$ (35,00\% MS, 135 DPP).

Verifica-se que em média os teores de proteína bruta na lâmina foliar dos híbridos, variaram de 10,93 a $13,87 \%$ na MS, não diferindo $(\mathrm{P}>0,05)$ entre híbridos. Estes resultados são próximos aos $12,2 \%$ encontrados por Johnson (1971).

Os teores de PB na lâmina foliar foram correlacionados negativamente com os teores de fibra em detergente ácido da lâmina foliar $\left(\mathrm{R}^{2}=-48,08 \%\right)$ e fibra em detergente neutro da lâmina foliar $\left(R^{2}=-61,53 \%\right)$. Observou-se ainda, correlações negativas nos teores de PB na lâmina foliar, em relação às percentagens de grão $\left(\mathrm{R}^{2}=-61,39 \%\right)$ e espiga na planta inteira $\left(R^{2}=-71,11 \%\right)$ e correlações positivas em relação às percentagens colmo + bainha $\left(\mathrm{R}^{2}=66,50 \%\right) \mathrm{e}$ lâmina foliar na planta inteira $\left(\mathrm{R}^{2}=64,09 \%\right)$.

Foi avaliada a concentração de nitrogênio insolúvel em detergente ácido (NIDA), em relação ao N total na lâmina foliar. O NIDA representa a fração do nitrogênio que não está disponível ao animal, considerado como indigestível durante a sua permanência no trato gastrintestinal. Segundo Van 
Tabela 2 - Equação de regressão para os teores de proteína bruta (\%PB), de nitrogênio insolúvel em detergente ácido (\%NIDA), de fibra em detergente neutro (\%FDN), de fibra em detergente ácido (\%FDA), de lignina da lâmina foliar dos híbridos de milho em diferentes estádios de maturação, em função de dias pós plantio (DPP)

Table 2 - Regression equation at percentage the crude protein (CP), the acid detergent insoluble nitrogen (\%ADIN), neuter detergent fiber (\%NDF), acid detergent fiber (\%ADF), lignin at leaf lamina the corn hybrid in function of the days after seeding (DAS)

\begin{tabular}{|c|c|}
\hline $\begin{array}{l}\text { Híbrido } \\
\text { Hybrid }\end{array}$ & $\begin{array}{l}\text { Equação de regressão } \\
\text { Regression equation }\end{array}$ \\
\hline P32R21 1 & $\mathrm{~PB}=552,8-10,99 * \mathrm{DPP}+0,07489 * \mathrm{DPP}^{2}-0,000172 * \mathrm{DPP}^{3}$ \\
\hline $\mathrm{P} 30 \mathrm{R} 07^{2}$ & $\mathrm{~PB}=552,8+1,068-10,99 * \mathrm{DPP}+0,07489 * \mathrm{DPP}^{2}-0,000172 * \mathrm{DPP}^{3}$ \\
\hline P3041 3 & $\mathrm{~PB}=552,8+1,943-10,99 * \mathrm{DPP}+0,07489 * \mathrm{DPP}^{2}-0,000172 * \mathrm{DPP}^{3}$ \\
\hline P30F33 4 & $\mathrm{~PB}=552,8+1,741-10,99 * \mathrm{DPP}+0,07489 * \mathrm{DPP}^{2}-0,000172 * \mathrm{DPP}^{3}$ \\
\hline $\mathrm{P} 30 \mathrm{~F} 80^{5}$ & $\mathrm{~PB}=552,8+2,622-10,99 * \mathrm{DPP}+0,07489 * \mathrm{DPP}^{2}-0,000172 * \mathrm{DPP}^{3}$ \\
\hline P32R21 & $\mathrm{NIDA}=-14845+329,5 * \mathrm{DPP}-2,422 * \mathrm{DPP}^{2}+0,005913 * \mathrm{DPP}^{3}$ \\
\hline P30R07 & $\mathrm{NIDA}=-14845+20644-119,9 * \mathrm{DPP}+0,8304 * \mathrm{DPP}^{2}-0,001914 * \mathrm{DPP}^{3}$ \\
\hline P3041 & $\mathrm{NIDA}=-14845+16397-31,18 * \mathrm{DPP}+0,2152 * \mathrm{DPP}^{2}-0,0004984 * \mathrm{DPP}^{3}$ \\
\hline P30F33 & $\mathrm{NIDA}=-14845+37915-480 * \mathrm{DPP}+3,325 * \mathrm{DPP}^{2}-0,007657 * \mathrm{DPP}^{3}$ \\
\hline P30F80 & $\mathrm{NIDA}=-14845+22973-165,9 * \mathrm{DPP}+1,129 * \mathrm{DPP}^{2}-0,002549 * \mathrm{DPP}^{3}$ \\
\hline P32R21 & $\mathrm{FDN}=-4689-101,5+106,3 * \mathrm{DPP}-0,7754 * \mathrm{DPP}^{2}+0,001886 * \mathrm{DPP}^{3}$ \\
\hline P30R07 & $\mathrm{FDN}=-4689+101,0 * \mathrm{DPP}-0,7134 * \mathrm{DPP}^{2}+0,001676 * \mathrm{DPP}^{3}$ \\
\hline P3041 & $\mathrm{FDN}=-4689+3088+36,18 * \mathrm{DPP}-0,2619 * \mathrm{DPP}^{2}+0,0006326 * \mathrm{DPP}^{3}$ \\
\hline P30F33 & $\mathrm{FDN}=-4689+354,4+93,34 *$ DPP-0,6588 $* \mathrm{DPP}^{2}+0,001547 * \mathrm{DPP}^{3}$ \\
\hline P30F80 & $\mathrm{FDN}=-4689+5852-20,21 * \mathrm{DPP}+0,1212 * \mathrm{DPP}^{2}-0,0002350 * \mathrm{DPP}^{3}$ \\
\hline P32R21 & $\mathrm{FDA}=-703,1-5999+135 * \mathrm{DPP}-0,9002 * \mathrm{DPP}^{2}+0,001998 * \mathrm{DPP}^{3}$ \\
\hline P32R07 & $\mathrm{FDA}=-703,1+17 * \mathrm{DPP}-0,1301 * \mathrm{DPP}^{2}+0,0003307 * \mathrm{DPP}^{3}$ \\
\hline P3041 & $\mathrm{FDA}=-703,1+1647-19,66 * \mathrm{DPP}+0,1405 * \mathrm{DPP}^{2}-0,0003315 * \mathrm{DPP}^{3}$ \\
\hline P30F33 & $\mathrm{FDA}=-703,1+3181-50,42 * \mathrm{DPP}+0,3449 * \mathrm{DPP}^{2}-0,0007819 * \mathrm{DPP}^{3}$ \\
\hline P30F80 & $\mathrm{FDA}=-703,1-3866+102 * \mathrm{DPP}-0,7513 * \mathrm{DPP}^{2}+0,001842 * \mathrm{DPP}^{3}$ \\
\hline P32R21 & $\mathrm{LIG}=536,3-3138+57,16 * \mathrm{DPP}-0,4167 * \mathrm{DPP}^{2}+0,001011 * \mathrm{DPP}^{3}$ \\
\hline P30R07 & $\mathrm{LIG}=536,3-10,97 * \mathrm{DPP}+0,07532 * \mathrm{DPP}^{2}-0,0001716 * \mathrm{DPP}^{3}$ \\
\hline P3041 & $\mathrm{LIG}=536,3-3008+52,16 * \mathrm{DPP}-0,3651 * \mathrm{DPP}^{2}+0,0008502 * \mathrm{DPP}^{3}$ \\
\hline P30F33 & $\mathrm{LIG}=536,3-1637+25,72 * \mathrm{DPP}-0,19760 * \mathrm{DPP}^{2}+0,0005015 * \mathrm{DPP}^{3}$ \\
\hline P30F80 & $\mathrm{LIG}=536,3+295,7-16,31 * \mathrm{DPP}+0,1063 * \mathrm{DPP}^{2}-0,0002289 * \mathrm{DPP}^{3}$ \\
\hline
\end{tabular}

DPP: colheita pós plantio (dias) (DAS: days after seeding, days).

1 Período de colheita de 125 a 151 DPP (Harvest period from 125 to 151 DAS).

2 Período de colheita de 128 a 156 DPP (Harvest period from 128 to 156 DAS).

3 Período de colheita de 127 a 156 DPP (Harvest period from 127 to 156 DAS).

4 Período de colheita de 129 a 157 DPP (Harvest period from 129 to 157 DAS).

5 Período de colheita de 135 a 164 DPP (Harvest period from 135 to 164 DAS).

Soest (1994), o NIDA é aquele nitrogênio lignificado e no sistema de proteína e energia líquida de Cornell, esta fração é denominada de fração C (indisponível) quando do fracionamento da proteína bruta.

Para os teores de NIDA em relação ao N total, na lamina foliar, houve diferença entre híbridos $(\mathrm{P}<0,01)$ e verificou-se efeito cúbico de DPP (Tabela 2).

Considerando a faixa de variação de 30 a $35 \%$ de MS, os maiores valores de NIDA em relação ao N total, foram observados para os híbridos superprecoce P32R21 de 47,78 a 42,39\% NIDA, aos 132 e 137 DPP e para o semiprecoce P30F80 de 45,56 a $44,53 \%$ de NIDA, aos 155 e 162 DPP. Os menores teores foram observados para o híbrido precoce P30F33 que variou de 36,69 a 30,06\% de NIDA e para o híbrido precoce P3041 que variou de 37,11 a
36,04\% de NIDA, sendo que o híbrido precoce P30R07 apresentou valor intermediário de 43,12 a 37,38\% de NIDA. O mesmo comportamento quando da redução nos teores de PB, considerando a faixa de 30 a $35 \%$ de MS, foi observado também no teores de NIDA, entretanto, considerando uma maior variação para os teores de MS de 30 a $45 \%$ de MS, observou-se um comportamento cúbico para os teores de NIDA.

Para os teores de fibra em detergente neutro (FDN) da lâmina foliar dos cinco híbridos de milho também foi observado efeito cúbico $(\mathrm{P}<0,01)$ para DPP (Tabela 2). Os maiores teores da FDN foram verificados para o híbrido semiprecoce P30F80, de 67,16 a 70,64\%, aos155 e 162 DPP, para faixa de variação de 30 a 35\% de MS. Os menores valores foram observados para o híbrido precoce P30F33, 
com pequena variação de 65,07 a 65,32\% de FDN, para os mesmos teores de MS acima citados. Ainda, considerando uma maior faixa de variação nos teores de MS da planta de 20,74 a 42,54\%, verifica-se pequena mudança nos teores de FDN em torno de duas a cinco unidades percentuais, respectivamente, para o híbrido o precoce P30F33 e o semiprecoce P30F80. Para o híbrido superprecoce P32R21, na faixa de MS de 30 a 35\%, os teores de FDN na lâmina foliar pouco variaram de 68,27 para 68,68\%, entretanto, para maior amplitude nos teores de MS de 25,85 a $39,27 \%$, observou-se um aumento em torno de oito unidades percentuais nos teores de FDN, de 64,96 a 73,25\%. Para os híbridos precoces P30R07 e P3041, os teores de FDN na lâmina foliar foram intermediários e variaram, em média, de $65,00 \%$ a $67,50 \%$, para teores de MS de 30 a 35\%. Estes resultados concordam com aqueles de Andrieu et al. (1993), em que os teores de FDN permaneceram relativamente constantes, durante o enchimento do grão.

Os resultados, obtidos por Johnson et al. (1985) para os teores da FDN na fração verde (colmo, folhas e palhas), foram de 71,60 e 72,60\%, para os híbridos FunksG-4858 e Pioneer 3147, respectivamente. Já os teores de FDN da fração verde relatados por Hunt et al. (1993) para os híbridos Pioneer 3377 e Pioneer 3389, foram de 58,40 e 65,60\%, respectivamente. Almeida Filho (1996), trabalhando também com a fração verde, encontrou valores que variaram de 72,75 a 77,56\% para a FDN, e Silva et al. (1994), avaliando planta inteira de híbridos de milho para ensilagem, encontraram variação entre 66,25 a $70,85 \%$ para a FDN. Todavia, Silva et al. (1999), avaliando a concentração de FDN na haste + folha, encontraram valores que variaram entre 55,03 a 67,42\%, para híbridos de milho no ano de 1995/96 e entre 61,05 a $71,18 \%$ de FDN, no ano de 1996/97. As altas temperaturas, durante o desenvolvimento da cultura, podem elevar os teores de FDN na planta (Struik, 1983). Os valores supracitados, de modo geral, são superiores aos encontrados neste experimento, porém há que considerar que os resultados do presente trabalho são baseados na lâmina foliar e não na fração verde ou planta inteira.

Os teores de FDN da lâmina foliar apresentaram correlações significativas e positivas com os teores de MS da planta $\left(\mathrm{R}^{2}=52,83 \%\right)$ e com os teores de fibra em detergente ácido da lâmina foliar $\left(\mathrm{R}^{2}=56,27 \%\right)$.

A fibra em detergente ácido (FDA), que inclui celulose e uma parte lignificada e indigestível, da lâmina foliar, diferiu $(\mathrm{P}<0,01)$ entre híbridos e também mostrou um comportamento cúbico $(\mathrm{P}<0,05)$ para DPP (Tabela 2). Os valores médios de FDA na lâmina foliar variaram entre 35,19 a 40,98\% .

O híbrido superprecoce P32R21 apresentou os menores valores de FDA na lâmina foliar. Para faixa entre 30 e $35 \%$ de MS na planta, variou de $28,15 \%$ (29,88\% MS, aos 132 DPP) a 34,60\% de FDA (34,51\% MS, aos 137 DPP). Os maiores teores da FDA foram observados para o híbrido semiprecoce P30F80, que variaram de 50,29 a 69,09\% aos 155 (29,69\% MS) e 162 DPP (34,78\% MS). Os demais híbridos precoces P30R07, P3041 e P30F33 apresentaram teores da FDA que variaram, em média, de 34,00 a 36,00\%, considerando-se os teores de MS da planta de 30 a $35 \%$.

Os valores médios da FDA na lâmina foliar são superiores às variações de 26,30 e 30,00\% e de 27,60 a $31,84 \%$ encontrados, respectivamente, por Hunt et al. (1993) e Almeida Filho et al. (1999), que apresentaram esses teores de FDA na fração verde $($ colmo + folha + palha).

Houve correlação significativa entre os teores de FDA da lâmina foliar e os teores de MS, nos diferentes estádios de maturação $\left(\mathrm{R}^{2}=42,81 \%\right)$.

$\mathrm{O}$ teor de lignina da lâmina foliar diferiu $(\mathrm{P}<0,01)$ para híbridos, como também mostrou efeito cúbico $(\mathrm{P}<0,01)$ em função DPP (Tabela 2). Os teores médios de lignina variaram de 4,85 a $7,88 \%$, tendo o híbrido superprecoce P32R21 apresentado o maior valor $(7,88 \%)$ e o híbrido precoce $\mathrm{P} 30 \mathrm{~F} 33$ (4,85\%), o menor. Estes resultados são superiores aos 3,40 e 3,80\% encontrados por Hunt et al. (1993) nos híbridos Pioneer, P3377 e P3389, respectivamente.

Considerando os teores de 30 a $35 \%$ de MS, recomendados para o processo de ensilagem, verificase que o híbrido precoce P30F33 apresentou a menor proporção de lignina na lâmina foliar com valores médios entre 5,02 e 3,14\% aos 131 e 141 DPP. O híbrido superprecoce P32R21 apresentou os maiores valores de lignina de 8,10 a 7,98 aos 132 e 137 DPP, com 29,88 e $34,51 \%$ MS, respectivamente. Para os híbridos precoces P30R07 e P3041 apresentaram como médias para esta faixa ( 30 a $35 \%$ MS) valores de 6,02 e 7,45\% de lignina na lâmina foliar. Já o híbrido semiprecoce P30F80, apresentou média de $5,89 \%$ de lignina, entre os teores de 30a 35\% de MS.

Segundo Jung (1989), a fração de lignina na parede celular da forragem está negativamente associada com a digestão da fibra pelo ruminante, 
onde, através de sua estrutura e tipo de ligações covalentes com a hemicelulose, torna a lignina o principal componente pela redução na qualidade da planta.

Com relação à fração colmo + bainha dos híbridos de milho, observa-se que os teores de proteína bruta (PB) na matéria seca diferiram entre híbridos $(\mathrm{P}<0,01)$ e apresentou efeito linear ( $\mathrm{P}<0,05)$ para DPP (Tabela 3 ). Assim, verifica-se que, com o aumento do estádio de maturação da planta, houve aumentos nos teores de PB do colmo + bainha. Os teores de PB do colmo + bainha, mesmo sendo significativos, a variação foi pequena entre os híbridos de milho, de 3,58 a 3,86\%, para os híbridos superprecoce P32R21 e semiprecoce P30F80, respectivamente, valores estes inferiores aos encontrados na literatura para avaliação de amostras de planta inteira (Caldwell \& Perry, 1971; Johnson et al., 1985; Quadros et al., 1994; Hunt et al.,
1993; Almeida Filho et al., 1999; Flaresso et al., 2000).

Variando os teores de MS na planta inteira de 30 a 35\%, o híbrido semiprecoce P30F80 apresentou os maiores valores de PB do colmo + bainha, porém com pequena mudança de 3,94 para $4,04 \%$, aos $155(29,69 \%$ MS) e 162 DPP (34,78\% MS). Já o híbrido superprecoce P32R21, aos 132 (29,88\% MS) e 137 DPP (34,51\% MS), apresentou os menores valores para PB do colmo + bainha, 3,48 e 3,59\%, respectivamente.

Para os teores de nitrogênio insolúvel em detergente ácido (NIDA), observou-se diferença $(\mathrm{P}<0,01)$ para os híbridos e efeito cúbico em função de DPP (Tabela 3).

Levando em consideração os teores de 30 a $35 \%$ de MS, verificou-se que, os híbridos precoces P3041 e P30R07, apresentaram, respectivamente, as maiores $(51,44$ a $60,33 \%$ de NIDA) e as menores $(40,78$ a

Tabela 3 - Equação de regressão e porcentagens médias dos teores de proteína bruta (PB), de nitrogênio em detergente ácido (NIDA), de fibra em detergente neutro (FDN), de fibra em detergente ácido (FDA), Lignina do colmo + bainha dos híbridos de milho, nos diferentes estádios de maturação, em função de dias pós plantio (DPP)

Table 3 - Regression equation and percentage mean at crude protein (CP), the acid insoluble nitrogen (ANID), neuter detergent fiber (NDF), neuter detergent acid (ADF), Lignin stem + sheath the corn hybrid at different stages maturity (days after seeding - DAS)

\begin{tabular}{|c|c|}
\hline $\begin{array}{l}\text { Híbrido } \\
\text { Hybrid } \\
\end{array}$ & $\begin{array}{l}\text { Equação de regressão } \\
\text { Regression equation }\end{array}$ \\
\hline P32R21 & $\mathrm{PB}=0,3861+0,02344 * \mathrm{DPP}$ \\
\hline P30R07 & $\mathrm{PB}=0,3861+1,955+0,01044 * \mathrm{DPP}$ \\
\hline P3041 & $\mathrm{PB}=0,3861+1,701+0,01237 * \mathrm{DPP}$ \\
\hline P30F33 & $\mathrm{PB}=0,3861+2,591+0,005835 * \mathrm{DPP}$ \\
\hline P30F80 & $\mathrm{PB}=0,3861+1,312+0,01447 * \mathrm{DPP}$ \\
\hline P32R21 & $\mathrm{NIDA}=3945-92,51 * \mathrm{DPP}+0,7241 * \mathrm{DPP}^{2}-0,001872 * \mathrm{DPP}^{3}$ \\
\hline P30R07 & $\mathrm{NIDA}=3945+9170-281,5 * \mathrm{DPP}+2,01 * \mathrm{DPP}^{2}-0,004756 * \mathrm{DPP}^{3}$ \\
\hline P3041 & $\mathrm{NIDA}=3945+24457-606,6 * \mathrm{DPP}+4,313 * \mathrm{DPP}^{2}-0,01019 * \mathrm{DPP}^{3}$ \\
\hline $\mathrm{P} 30 \mathrm{~F} 33$ & $\mathrm{NIDA}=3945-4851+15,86 * \mathrm{DPP}-0,08285 * \mathrm{DPP}^{2}+0,0001299 * \mathrm{DPP}^{3}$ \\
\hline P30F80 & $\mathrm{NIDA}=3945-6312+38,69 * \mathrm{DPP}-0,1924 * \mathrm{DPP}^{2}+0,000279 * \mathrm{DPP}^{3}$ \\
\hline P32R21 & $\mathrm{FDN}=-935,6+23,18 * \mathrm{DPP}-0,1767 * \mathrm{DPP}^{2}+0,0004485^{*} \mathrm{DPP}^{3}$ \\
\hline P30R07 & $\mathrm{FDN}=-935,6-1717+57,38 * \mathrm{DPP}-0,4011 * \mathrm{DPP}^{2}+0,0009314 * \mathrm{DPP}^{3}$ \\
\hline P3041 & $\mathrm{FDN}=-935,6+1980-20,1 * \mathrm{DPP}+0,1391 * \mathrm{DPP}^{2}-0,00032 * \mathrm{DPP}^{3}$ \\
\hline P30F33 & $\mathrm{FDN}=-935,6+2131-24,11 * \mathrm{DPP}+0,1735 * \mathrm{DPP}^{2}-0,0004167 * \mathrm{DPP}^{3}$ \\
\hline P30F80 & $\mathrm{FDN}=-935,6+8073-139,4 * \mathrm{DPP}+0,9137 * \mathrm{DPP}^{2}-0,00199 * \mathrm{DPP}^{3}$ \\
\hline P32R21 & $\mathrm{FDA}=-899,3+20,29 * \mathrm{DPP}-0,1451 * \mathrm{DPP}^{2}+0,0003470 * \mathrm{DPP}^{3}$ \\
\hline P30R07 & $\mathrm{FDA}=-899,3+2762-39,49 * \mathrm{DPP}+0,2841 * \mathrm{DPP}^{2}-0,0006749 * \mathrm{DPP}^{3}$ \\
\hline P3041 & $\mathrm{FDA}=-899,3+3395-50,23 * \mathrm{DPP}+0,3419 * \mathrm{DPP}^{2}-0,0007698 * \mathrm{DPP}^{3}$ \\
\hline $\mathrm{P} 30 \mathrm{~F} 33$ & $\mathrm{FDA}=-899,3+911,3-0,0789 * \mathrm{DPP}+0,007015 * \mathrm{DPP}^{2}-0,000033 * \mathrm{DPP}^{3}$ \\
\hline P30F80 & $\mathrm{FDA}=-899,3-4332+100,6 * \mathrm{DPP}-0,6331 * \mathrm{DPP}^{2}+0,001317 * \mathrm{DPP}^{3}$ \\
\hline $\mathrm{P} 32 \mathrm{R} 21$ & $\mathrm{LIG}=3138-69,27 * \mathrm{DPP}+0,5097 * \mathrm{DPP}^{2}-0,001246 * \mathrm{DPP}^{3}$ \\
\hline P30R07 & $\mathrm{LIG}=3138-4950+38,5 * \mathrm{DPP}-0,2697 * \mathrm{DPP}^{2}+0,0006264 * \mathrm{DPP}^{3}$ \\
\hline P3041 & $\mathrm{LIG}=3138-8232+108,5 * \mathrm{DPP}-0,766 * \mathrm{DPP}^{2}+0,001798 * \mathrm{DPP}^{3}$ \\
\hline P30F33 & $\mathrm{LIG}=3138-3764+13,27 * \mathrm{DPP}-0,09149 * \mathrm{DPP}^{2}+0,0002087 * \mathrm{DPP}^{3}$ \\
\hline P30F80 & $\mathrm{LIG}=3138-1716+25,49 * \mathrm{DPP}-0,1504 * \mathrm{DPP}^{2}+0,0006264 * \mathrm{DPP}^{3}$ \\
\hline
\end{tabular}

DPP: colheita pós plantio (dias) (DAS: days after seeding, days).

1 Período de colheita de 125 a 151 DPP (Harvest period from 125 to 151 DAS).

2 Período de colheita de 128 a 156 DPP (Harvest period from 128 to 156 DAS).

3 Período de colheita de 127 a 156 DPP (Harvest period from 127 to 156 DAS).

4 Período de colheita de 129 a 157 DPP (Harvest period from 129 to 157 DAS).

5 Período de colheita de 135 a 164 DPP (Harvest period from 135 to 164 DAS). 
43,20\% de NIDA) proporções de NIDA no colmo + bainha. Para a silagem de milho da planta inteira, os teores de NIDA são, em média, de 15,00\% (Valadares Filho, 1994).

Observou-se que em média os teores de PB presentes no colmo+bainha para os híbridos avaliados, com o avanço de dias pós plantio (DPP), apresentaram pequena mudança (em torno de 0,34 unidades percentuais), porém o mesmo não ocorreu com a sua disponibilidade, uma vez que os teores de NIDA variaram em média de 15 unidades percentuais.

Também foi observado efeito cúbico dos teores de FDN do colmo + bainha dos híbridos de milho e DPP $(\mathrm{P}<0,01)$ (Tabela 3). Os teores de FDN do colmo + bainha na faixa de 30 a $35 \%$ de MS, praticamente não variaram. O híbrido precoce $\mathrm{P} 3041$ apresentou os maiores valores, variando de 78,68 (29,88\% MS) a $78,91 \%$ (34,81\% MS), aos 140 e 145 DPP. Os teores médios da FDN do colmo + bainha, para os diferentes estádios de maturação, dos cinco híbridos de milho, foram de 76,51, 71,58, 74,05, 77,53, 79,07\% para os híbridos precoce $\mathrm{P} 30 \mathrm{~F} 33$, semiprecoce $\mathrm{P} 30 \mathrm{~F} 80$, precoce P30R07, superprecoce P32R21 e precoce P3041, respectivamente, diferindo entre si $(\mathrm{P}<0,01)$.

Os teores médios da FDN no colmo + bainha foram superiores àqueles observados na literatura (Johnson et al., 1985, Hunt et al., 1993, Almeida Filho 1996, Silva et al., 1994, Silva et al., 1999). Estes autores trabalharam com a fração verde da planta (folha, haste, palha) ou planta inteira. Já neste estudo trabalhou-se com colmo + bainha e, os cortes das plantas a campo foram realizados a $45 \mathrm{~cm}$ do solo, o que pode ter ocasionado a maior concentração de FDN.

Segundo Almeida Filho (1996), o aumento no teor da FDN de 4 a 5 unidades percentuais na fração verde, entre híbridos de milho, poderia influenciar na qualidade da forragem pela diminuição do conteúdo celular, parte mais digestível e de melhor qualidade. Porém, Deinum (1988) relatou que a degradabilidade da parede celular da fração verde foi a principal variável associada a digestibidade "in vitro" da planta de milho e que, híbridos de milho com menores teores de FDN e maiores proporções de espiga, na matéria seca, nem sempre são mais degradáveis. Isto pode estar associado ao fato de que a maior digestão de amido pode reduzir a digestibilidade da celulose (Demarquilly, 1994) e a digestibilidade da ração total misturada não é melhorada.

Os teores de fibra em detergente ácido (FDA) do colmo + bainha dos híbridos, com valores entre 46,04 a 54,48\%, diferiu $(\mathrm{P}<0,01)$ entre híbridos, também mostrando comportamento cúbico $(\mathrm{P}<0,01)$ em função de DPP, cujas equações são apresentadas na Tabela 3. O híbrido precoce P30R07, para a faixa de 30 a $35 \%$ MS, apresentou pequena variação nos teores de FDA, de 47,30 (33,13\% MS) a 48,76\% (34,39\% MS), aos 128 e 135

DPP. Já o híbrido semiprecoce P30F80 apresentou a maior variação, de $55,81 \%$ de FDA $(29,69 \%$ MS $)$ a $50,08 \%$ de FDA $(34,78 \%$ MS), aos 155 e 162 DPP.

Os valores do presente trabalho são superiores aos encontrados na literatura para os teores de FDA, devendo-se levar em consideração que tais valores são referentes ao colmo + bainha e ao corte da planta feito a $45 \mathrm{~cm}$ do solo. Schmid et al. (1976), avaliando 11 cultivares de milho para silagem, encontrou para FDA na planta inteira valores entre 25,1 a $32,9 \%$, para os híbridos de milho AES 101 e Penn syn 2, respectivamente.

Os teores de lignina do colmo + bainha para os híbridos de milho apresentaram efeito cúbico $(\mathrm{P}<0,01)$ em função de DPP (Tabela 3). Para a faixa de 30 a 35\% MS, o híbrido superprecoce apresentou os menores valores para teores de lignina do colmo + bainha, variando de 9,61 (28,88\% MS) a 10,66\% (34,51\% MS) aos 132 e 137 DPP. Todavia, os híbridos precoces P30R07 e P3041 apresentaram os maiores valores entre 14,50 a $16,00 \%$ de lignina. O semiprecoce $\mathrm{P} 30 \mathrm{~F} 80$ variou de 10,07 a $13,05 \%$ e o precoce $\mathrm{P} 30 \mathrm{~F} 33$ não variou, com média de 11,35\%, considerando teores de 30 a $35 \%$ de MS.

Os teores médios de lignina mostraram pequena variação entre os híbridos, de 10,10 a 15,30\%. Penati (1995), estudando a haste de vinte cultivares de milho, encontrou variação entre 6 a 12\% para lignina, próximos aos valores encontrados neste experimento.

\section{Conclusões}

Verificaram-se pequenos decréscimos nos teores de proteína e praticamente não alteraram os teores de amido, na fração grão.

Constatou-se redução nos teores de proteína e nos teores de nitrogênio insolúvel em ácido (NIDA) na fração lâmina foliar e o inverso foi observado na fração colmo + bainha, em que o teor de proteína se elevou ligeiramente e os teores de NIDA aumentaram acentuadamente.

Houve aumentos nos teores de fibra em deter- 
gente neutro, fibra em detergente ácido e lignina da fração lâmina foliar, porém esses nutrientes na fração colmo + bainha dos híbridos de milho, praticamente, não variaram.

\section{Agradecimento}

À Empresa Sementes Pioneer, pela oportunidade oferecida e pelo apoio para a realização deste trabalho.

À Fundação $\mathrm{ABC}$, pelo desenvolvimento do campo experimental.

\section{Literatura Citada}

ANDRIEU, J.; DEMARQUILLY, C.; DARDENNE, P. et al. Composition and nutritive value of whole maize plants fed fresh to sheep. 1. Factors of variation. Animal Zootech, v.42, p.221-249, 1993.

ALMEIDA FILHO, S.L. Avaliação de cultivares de milho (Zea mays L.) para silagem Viçosa, MG: Universidade Federal de Viçosa, 1996. 52p. Dissertação (Mestrado em Zootecnia) - Universidade Federal de Viçosa, 1996.

ALMEIDA FILHO, S.F.; FONSECA, D.M.; GARCIA, R. et al. Características agronômicas de cultivares de milho (Zea mays L.) e qualidade dos componentes e da silagem. Revista Brasileira de Zootecnia, v.28, n.1, p.7-13, 1999.

ARIELI, A.; BRUCKENTAL, I.; KEDAR, O. et al. In sacco disappearance of starch nitrogen and fat in processed grains. Animal Feeding Science Technology, v.51, p.287, 1995.

BARNES, R.F. Use of in vitro fermentation techniques for estimating forage digestibility and intake. Agronomy Journal, v.57, n.2, p.213, 1965.

BARRIÈRE, Y.; ARGILLIER, O.; MICHALET-DOREAU, B. et al. Relevant traits, genetiv variation and breeding satrategies en early silage maize. Agronomie, v.17, p.395-411, 1997.

BEZERRA, E.S.; Von TIESENHAUSEN, I.M.E.V.; OLIVEIRA, A.I.G. et al. Valor nutricional das silagens de milho, milho associado com sorgo e rebrotas de sorgo. Revista Brasileira de Zootecnia, v.22, n.6, p.1045-1054, 1993.

CALDAS NETO, S.F.; ZEOULA, L.M.; BRANCO, A.F. et al. Mandioca e resíduos das farinheiras na alimentação de ruminantes: Digestibilidade total e parcial. Revista Brasileira de Zootecnia, v.29, n.6, p.2099-2108, 2000.

CABON, G. Diversity of chemical composition evolutions of maize the weeks before harvesting Indicators of physiological stage. In: COLLOQUE MAÏS ENSILAGE. 1., 1996, Nantes. Proceedings... Nantes-France, 1996. p.43-50.

CALDWELL, D.M.; PERRY, T.W. Relationships between stage of maturity of the corn plant time of harvest for corn silage and chemical composition. Journal of Dairy Science, v.54, n.4, p.533-536, 1971.

CRAMPTON, A.M. Interrelations between digestible nutrient and energy content, voluntary dry matter, intake and the overall. Journal of Animal Science, v. 16, n.3, p.546-552, 1957.

DEINUM, B.; STEG, A.; HOF, G. Measurement and prediction of digestibility of forage maize in the Netherlands. Animal Feeding Science and Technology, v.10, n.4, p.301-313, 1984.
DEMARQUILLY, C. Facteurs de variation de la valeur nutritive du mais ensilage. INRA. Production Animal, v.7, n.3, p.177-189, 1994.

EMPRESA BRASILEIRA DE PESQUISA AGROPECUÁRIA - EMBRAPA. Avaliação de cultivares de milho para silagem - Safra 94/95. Juiz de Fora: CNPGL/EMBRPA, 1997. 18p. (Relatório)

FERRI, M.G. Fisiologia vegetal 1 2.ed. São Paulo: EPU, 1985. 362p.

FLARESSO, J.A.; GROSS, C.D.; ALMEIDA, E.D. Cultivares de milho (Zea mays L. e Sorgo (Sorghum bicolor (L.) Moench.) para ensilagem no alto Vale do Itajaí, Santa Catarina.Revista Brasileira de Zootecnia, v.29, n.6, p.1608-1615, 2000.

FREGADOLLI, F.L.; ZEOULA, L.M; PRADO, I.N. et al. Efeito das fontes de amido e nitrogênio de diferentes degradabilidades ruminais. 1: Digestibilidades parcial e total. Revista Brasileira de Zootecnia, v.30, n.3, p.858-869, 2001.

GUIMARÃES, P.E.O.; PACHECO, C.A. Milho com alto valor nutricional. In: WORKSHOP SOBRE QUALIDADE DO MILHO, 1997, Dourados. Anais... Dourados: EMBRAPA, 1997. p.22-32.

HUNTER, R.B. Selection and evaluation procedures for whole plant corn silage. Canadian Journal Animal Science, v. 58 , n.7, p.661-678, 1978.

HUNT, C.W.; KEZAR, W.; HINMAN, D.D. et al. Effects of hybrid and ensiling and without a microbial inoculant on the nutritional characteristics of whole plant corn. Journal of Animal Science, v.71, n.1, p.38-43, 1993.

INSTITUT NATIONAL DE LA RECHERCHE AGRONOMIQUE - INRA. Rencontres chercheurs-éleveurs. Production Laitiere Magazine, v.277, n.2, p.42-50, 1998.

JOHNSON. R.R.; FARIA, U.P.; Mc CLURE, K.E. Effects of maturity on chemical composition and digestibility of bird resistant sorghum plants when fed to sheep as silage.Journal of Animal Science, v.33, n.5, p.1102-1109, 1971.

JOHNSON JR, J.C.; MONSON, W.G.; PETLIGREW, W.T. Variation in nutritive value of corn hybrids for silage. Nutrition Reports International, v.32, n.4, p.953-958, 1985.

JOHNSON, T.R. Fuentes alternas de almidón. Alimentos balanceados para animales, p.19-25, 1998.

JUNG, H.G. Forage lignins and their effects on fiber digestibility. Agronomie Journal, v.81, p.33-38, 1989.

MAYOMBO, A.P.; DUFRASNE, I.; HORNICK, J.L. et al. Influencie du stade de maturité de la plante de may recolteé pour ensilage sur la composition, la digestibilité aparente, les caractéristiques de fermentation dans le rume et les performances zootechniques chez le taurillon à I'engraissement. Animal Zootech, v.46, p.43-55, 1997.

NELDER, J.A.; WEDDERBURN, R.W.M. Generalized linear models. Journal of the Royal Statistical Society, v.A135, p.370-384, 1972.

PENATI, M.C. Relação de alguns parâmetros agronômicos e bromatológicos de híbridos de milho (Zea mays L.) com a produção, digestibilidade e teor de matéria seca na planta. Piracicaba: Escola Superior de Agricultura "Luiz de Queiroz", 1995. 97p. Dissertação (Mestrado em Agronomia) - Escola Superior de Agricultura "Luiz de Queiroz", 1995.

PEREIRA, J.R.A.; ROSSI, P. Manual prático de avaliação nutricional de alimentos. Piracicaba: Escola Superior de Agricultura "Luiz de Queiroz", 1995. 34p.

QUADROS, F.L.F.; GENRO, T.C.M.; ARAÚJO, J.B.E. et al. 
Qualidade da silagem de híbridos de milho (Zea mays L.) e sorgo (Sorghum sp.). In: REUNIÃO ANUAL DA SOCIEDADE BRASILEIRA DE ZOOTECNIA, 31., 1994, Maringá. Anais... Paraná: Sociedade Brasileira de Zootecnia, 1994. p.357.

SCHMID, A.R.; GOODRICH, R.D.; JORGAN, R.M. et al. Relationships among agronomic characteristics of corn and sorghum cultivars and silage quality. Agronomie Science, v.68, n.1, p.403-406, 1976.

STRUIK, P.C. Physiology of forage maize (Zea mays, $L_{\text {. }}$ ) in relation to its production and quality. Wageningen: Pudoc, 1983. 252p.

SILVA, A.W.L.; ALMEIDA, M.L.; MAFRA, A.L. et al. Avaliação de híbridos e variedades de milho para ensilagem. II - Características químico-bromatológicas do material na colheita. In: REUNIÃO ANUAL DA SOCIEDADE BRASILEIRA DE ZOOTECNIA, 31., 1994, Maringá. Anais... Viçosa, MG: Sociedade Brasileira de Zootecnia, 1994. p.345.

SILVA, D.J. Análise de alimentos (Métodos químicos e biológicos). Viçosa, MG: Universidade Federal de Viçosa, 1998. 166p.
SILVA, L.F.P., MACHADO, P.F., FRANCISCO JR., J.C. et al. Características agronômicas e digestibilidade "in situ"da fração volumosa de híbridos de milho para silagem.Scientia Agrícola, v.56, n.1, p.171-183, 1999.

VALADARES FILHO, S.C. Avaliação dos alimentos. Simpósio Internacional de Produção de Ruminantes. In: REUNIÃO ANUAL DA SOCIEDADE BRASILEIRA DE ZOOTECNIA, 31., 1994, Maringá. Anais... Viçosa, MG: Sociedade Brasileira de Zootecnia, 1994. p.95-118.

Van SOEST, P.J. Nutritional ecology of the ruminant. 2.ed. Corvalis: O \& B Books, 1994.

Recebido em: 28/02/02

Aceito em: 30/10/02 